REVIEW

\title{
The accuracy of diagnostic tests for GH deficiency in adults: a systematic review and meta-analysis
}

\author{
Ahmad Hazem ${ }^{2}$, Mohamed B Elamin ${ }^{1}$, German Malaga ${ }^{4}$, Irina Bancos ${ }^{1,5}$, Yolanda Prevost ${ }^{4}$, \\ Claudia Zeballos-Palacios ${ }^{4}$, Edgar R Velasquez ${ }^{4}$, Patricia J Erwin ${ }^{1}$, Neena Natt ${ }^{1,5}$, Victor M Montori ${ }^{1,5}$ \\ and Mohammad Hassan Murad ${ }^{1,3}$ \\ ${ }^{1}$ Knowledge and Evaluation Research Unit, Mayo Clinic, 200 First Street SW, Rochester, Minnesota 55905, USA, ${ }^{2}$ Department of Internal Medicine, \\ University of North Dakota, Fargo, North Dakota, USA, ${ }^{3}$ Division of Preventive, Occupational and Aerospace Medicine, Mayo Clinic, Rochester, Minnesota, \\ USA, ${ }^{4}$ Universidad Peruana Cayetano Heredia, Lima, Peru and ${ }^{5}$ Division of Endocrinology, Diabetes, Metabolism, Nutrition, Mayo Clinic, Rochester, \\ Minnesota, USA
}

(Correspondence should be addressed to M Hassan Murad at Knowledge and Evaluation Research Unit, Mayo Clinic; Email: murad.mohammad@mayo.edu)

\begin{abstract}
Context: The diagnostic accuracy of tests used to diagnose GH deficiency (GHD) in adults is unclear. Objective: We conducted a systematic review and meta-analysis of studies that provided data on the available diagnostic tests.

Data sources: We searched electronic databases (MEDLINE, EMBASE, Cochrane CENTRAL, Web of Sciences, and Scopus) through April 2011.

Study selection: Review of reference lists and contact with experts identified additional candidate studies. Reviewers, working independently and in duplicate, determined study eligibility.

Data extraction: Reviewers, working independently and in duplicate, determined the methodological quality of studies and collected descriptive, quality, and outcome data.

Data synthesis: Twenty-three studies provided diagnostic accuracy data; none provided patient outcome data. Studies had fair methodological quality, used several reference standards, and included over 1100 patients. Several tests based on direct or indirect stimulation of GH release were associated with good diagnostic accuracy, although most were assessed in one or two studies decreasing the strength of inference due to small sample size. Serum levels of GH or IGF1 had low diagnostic accuracy. Pooled sensitivity and specificity of the two most commonly used stimulation tests were found to be 95 and $89 \%$ for the insulin tolerance test and 73 and $81 \%$ for the GHRH + arginine test respectively. Metaanalytic estimates for accuracy were associated with substantial heterogeneity.

Conclusion: Several tests with reasonable diagnostic accuracy are available for the diagnosis of GHD in adults. The supporting evidence, however, is at high risk of bias (due to heterogeneity, methodological limitations, and imprecision).
\end{abstract}

European Journal of Endocrinology 165 841-849

\section{Introduction}

GH and the insulin-like growth factor 1 (IGF1) are involved in the regulation of somatic growth in children. In adults, this axis plays a role in maintaining normal body composition, skeletal mass, cardiovascular risk factors, and physical and physiological functioning (1). GH deficiency (GHD) has been related to insulin insensitivity, increased body fat, and decreased muscle mass; other studies have implicated that low levels of IGF1 are associated with increased risks of myocardial infarction, ischemic cardiac disease, and stroke (2). Thus, there has been interest in the clinical use of GH replacement in patients with GHD with the expectation that this agent could normalize body composition, enhance physical function, and prevent cardiovascular disease.

Among other indications, GH is approved for use in patients with hypothalamic-pituitary disease and GHD (3). GH is commonly used as an 'anti-aging agent' in patients without established deficit; in such instance, the evidence does not suggest substantial benefit (4). The therapeutic recommendation to use GH, therefore, rests in part on the ability to clinically diagnose patients who are truly deficient.

Expert reviews and consensus statements consider insulin-induced hypoglycemia (insulin tolerance test; ITT) as the reference standard for the diagnosis of this condition $(3,5)$. Alternative stimulation tests use $\mathrm{GHRH}+$ arginine, $\mathrm{GHRH}+\mathrm{GH}$-releasing peptide 
(GHRP), glucagon stimulation, and GHRP. To date, a summary of the available literature assessing the accuracy of the available tests for GHD in adult patients suspected of having the condition has not been conducted.

The aim of this systematic review and meta-analysis is to appraise and summarize the available evidence of the diagnostic accuracy of tests for GHD in adults.

\section{Materials and methods}

The protocol for this review is consistent with the available methodological guidelines for conducting diagnostic accuracy systematic reviews (6).

\section{Eligibility criteria}

We included cross-sectional and longitudinal studies that enrolled adult patients suspected of having GHD, i.e. clinicians had true diagnostic uncertainty about the patients' GH status. Studies that enrolled patients with pre-existing diagnosis of GHD, as well as those that enrolled patients who were clearly healthy, were excluded because they would likely overestimate the diagnostic accuracy of the tests (7). Eligible studies assessed the accuracy of diagnostic tests by evaluating the true disease status in all enrolled participants according to a reference standard. We accepted any reference standard chosen by the included studies' authors. When a reference standard was either unclear or not specified, we chose one of the tests of interest reported in the same study as a reference standard, usually opting for the ITT when available.

The ideal study design for our purpose was a randomized trial of testing treatment strategies in adult patients with suspected $\mathrm{GH}$ that evaluate a test for GHD in one arm versus no test or an alternative test. This design does not only yield accuracy data but also evidence about the utility of a particular management option based on a diagnostic test. However, we did not find any studies with such design.

\section{Study identification and selection}

An expert reference librarian (P J E) designed and conducted an electronic search strategy with input from study investigators with expertise in conducting systematic reviews ( $\mathrm{M} \mathrm{H} \mathrm{M}$ and $\mathrm{V} \mathrm{M} \mathrm{M}$ ). In order to identify eligible studies, we searched electronic databases (MEDLINE, EMBASE, Web of Science, Scopus, and citation search for key articles) through April 2011. The detailed search strategy is available on request. Furthermore, we sought references from experts in the field.

Two reviewers, working independently, considered the potential eligibility of each of the abstracts and titles that resulted from executing the search strategy.
Following the same procedures, reviewers evaluated the full-text reports (all available versions of each study) for eligibility. Subsequently, disagreements were harmonized by consensus; if not possible, by arbitration (i.e. a third reviewer adjudicated the disagreement).

\section{Data extraction}

Reviewers working independently and in duplicate used a standardized web-based form to extract the description of study participants, comorbidities, and chosen reference standard and cutoff value.

To assess diagnostic accuracy, we used the cutoff values chosen by the study authors. When multiple or no cutoff values were reported, we tended to borrow a cutoff value from another study that described the same test. In the instances that a study was assessing a test that had not been described in the previous literature, we chose the cutoff value that yielded the highest diagnostic accuracy of the test.

\section{Author contact}

Letters were sent to the corresponding authors (or if not reported the first and last authors) of each of the 28 studies that reached data extraction level by electronic mail (regular mail when an e-mail was not obtainable). We asked authors to verify the data we extracted and to complete missing data that we could not identify in the published record.

\section{Statistical analysis}

We used Meta-DiSc Software for Meta-analysis for Screening and Diagnostic tests version 1.4. We used random effect meta-analyses to pool the sensitivities, specificities, likelihood ratios, and diagnostic odds ratio (DOR) and estimate the 95\% confidence intervals for the outcomes.

The DOR of a test describes the ratio of the odds of a positive test result in patients with disease compared to patients without disease (8) and can be calculated as the ratio of the likelihood ratios for a positive and a negative test. Its main advantage lies in it being a single value that is indicative of a general test performance compared to the gold standard.

Summary receiver operating characteristic (ROC) curves facilitate visual assessment of the consistency of results across studies and the accuracy of the test, estimated by the area under the summary ROC curve, in differentiating between patients with GHD and patients without GHD. Unlike ROC curves in which individual data points represent different test cutoffs, each point in a summary ROC curve represents a study (9). In order to assess the inconsistency across studies, we have used the $I^{2}$ statistic, which represents the proportion of variability across studies that is not attributable to 
chance. $I^{2}$ values of 25,50 , and $75 \%$ indicate low, moderate, and high heterogeneity respectively.

\section{Subgroup analyses}

A priori hypotheses to explain the potential heterogeneity across studies included choice of reference standard, history of childhood onset GHD, presence of other pituitary hormone deficiencies, presence of known pituitary disease (history of meningitis, brain trauma, subarachnoid hemorrhage, and head irradiation), and choice of threshold (data driven, assay driven, from previous study). We tested these hypotheses using a test for interaction (10) considering $P<0.05$ as significant. There were not enough studies to use meta-regression as a strategy to identify predictors of test accuracy and explain inconsistency in results across studies.

\section{Results}

\section{Study identification}

Initial search of the literature yielded 952 publications, of which 117 were potentially relevant to this review based on the titles and abstracts. After full-text review, we found 28 eligible studies. We excluded seven studies from analysis because they did not report sufficient data for meta-analysis or did not measure the outcomes of interest. Attempts had been made to contact the authors of these studies and were either unsuccessful or unfruitful (11-18).

We asked authors to verify the data we extracted and to complete missing data that we could not identify in the published record. We were able to establish contact with $17(60 \%)$ of the authors of the 28 studies, of whom $14(82 \%)$ responded either by providing missing data or by confirming the accurate representation of their studies.

\section{Study characteristics}

Table 1 summarizes the baseline characteristics of eligible studies. Fifteen studies assessed the diagnostic accuracy of the serum IGF1, six the GHRH+arginine stimulation test (AST), three the ITT, three the serum GH levels, two the GHRP6, two the GHRH+GHRP6, two the GHRH + pyridostigmine, two the GHRH stimulation test, one the acipimox $+\mathrm{GHRH}$ test, one the hexarelin stimulation test, one the GHRH + GHRP2 test, one the GHRH+clonidine test, one the AST, one the glucagon stimulation test, and one the GHRH+ somatostatin (SMS) test.

Table 1 Characteristics of included studies. The patient characteristic categories in the table are not mutually exclusive and the percentages do not add to $100 \%$.

\begin{tabular}{|c|c|c|c|c|c|c|c|c|c|}
\hline \multirow[b]{2}{*}{ Studies } & \multicolumn{2}{|c|}{ Population characteristics } & \multicolumn{5}{|c|}{ Population description (\% from total) } & \multirow[b]{2}{*}{$\%$ men } & \multirow[b]{2}{*}{ Reference standard } \\
\hline & Age $(y ; \pm$ s.D. or Range $)$ & Size & $\mathrm{GHD}^{*}$ & CGHD & $\begin{array}{l}\text { PD without } \\
\text { PHD }\end{array}$ & $\begin{array}{l}\text { other } \\
\text { PHD }\end{array}$ & $\begin{array}{l}\text { Other } \\
\text { COM }\end{array}$ & & \\
\hline (1) & $36.4 \pm 2.1$ & 40 & NR & 47.5 & NR & 80 & NR & 73 & ITT \\
\hline (32) & R: $18-75$ & 49 & 4.1 & NR & NR & 95.9 & NR & 43 & ITT \\
\hline (33) & M: 39.7, F: 40.3 & 47 & 0 & 4 & NS & NS & 96 & 55 & ITT \\
\hline (34) & $52(23-77)$ & 34 & NR & NR & 70.6 & 29.4 & NR & 41 & ITT \\
\hline (29) & $\mathrm{R}: 28-64$ & 49 & NR & 0 & NR & 100 & NR & 53 & ITT \\
\hline (35) & $26(20-33)$ & 43 & NR & NR & 100 & NR & NR & 51 & ITT \\
\hline (36) & $65.8(60-72)$ & 18 & NR & NR & NR & 100 & 5.6 & 50 & $\mathrm{GHRH}+$ arginine \\
\hline (37) & $19.2 \pm 0.2$ (S.E.M.) & 152 & NR & 100 & NR & NR & NR & 56 & $\mathrm{GHRH}+$ arginine \\
\hline (9) & $23(1 \overline{6}-35.7)$ & 49 & NR & NR & 95.9 & 4.1 & NR & 67 & ITT \\
\hline (38) & 24.3 & 11 & NR & NR & 100 & NR & NR & 73 & ITT \\
\hline (39) & $46 \pm 16$ & 142 & NR & NR & NR & 100 & NR & 57 & ITT \\
\hline (40) & $43 . \overline{1}(21-59)$ & 26 & NR & NR & 30.8 & 69.2 & NR & 50 & ITT \\
\hline (41) & 24.5 & 108 & NR & 100 & NR & NR & NR & 68 & Clonidine \\
\hline (42) & $25.7 \pm 5.7$ & 69 & NR & 100 & NR & NR & NR & 58 & $\mathrm{GHRH}+\mathrm{PD}$ \\
\hline (43) & $\mathrm{R}: 18-59$ & 36 & 0 & 19.44 & 16.66 & 63.88 & 0 & 61 & ITT \\
\hline (44) & $53.32(31-76)$ & 19 & NR & NR & 57.9 & 42.1 & NR & 578 & AST \\
\hline (45) & R: 19-66 & 20 & NR & NR & 45 & 55 & NR & 55 & ITT \\
\hline (46) & $23.2 \pm 1.4$ & 22 & NR & NR & 100 & NR & NR & 64 & ITT \\
\hline (47) & $40.2 \pm 12.1$ & 21 & NR & NR & 100 & NR & NR & 71 & ITT \\
\hline (48) & $41 \pm \overline{13}$ & 30 & NR & NR & 53.3 & 46.7 & NR & 50 & $\begin{array}{l}\text { Concordance of ITT, AST, } \\
\text { and GHRH+IGF1 in } \\
\text { addition to a positive } \\
\text { test if discordant }\end{array}$ \\
\hline (49) & $53 \pm 2$ (S.E.M.) & 35 & NR & 0 & 37.1 & 62.9 & NR & 63 & ITT \\
\hline (50) & 22.5 & 6 & NR & 100 & NR & NR & NR & 50 & $\mathrm{GHRH}+\mathrm{PD}$ \\
\hline (51) & 35.76 & 138 & NR & 0 & 87 & 13 & NR & 71 & Glucagon stimulation test \\
\hline
\end{tabular}

GHD, GH deficiency; NR, not reported; ITT, insulin tolerance test; PD, pyridostigmine; AST, arginine stimulation test; IGF1, insulin-like growth factor 1, CGHD, childhood onset GHD; PD, pituitary disease; PHD, pituitary hormone deficiencies; COm, comorbidities. * presumed GHD, otherwise healthy. 


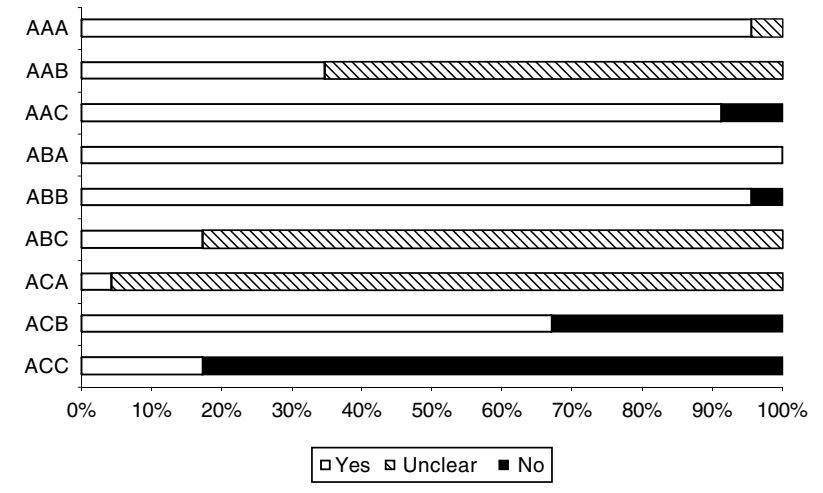

Figure 1 Reported QUADAS quality elements. AAA, was the spectrum of pts representative of pts who will receive the test in practice? $A A B$, is the time period between the index and the reference short enough to be reasonably sure target condition did not change? AAC, did the whole sample or random selection of sample receive verification using a reference standard? ABA, did pts receive same reference standard regardless of the index test results? $A B B$, was the reference standard independent of the index test? $A B C$, were the results of the index test interpreted without knowledge of the results of the reference standard? ACA, were the results of the reference standard interpreted without knowledge of the results of the index test? ACB, were the same clinical data available when study was done as would be when test is used in practice? ACC, were drop-outs explained?

\section{Study quality}

Figure 1 provides a summary of the methodological quality of the 23 included studies. The selection criteria were clearly described in 18 (78\%) studies. Participants $21(91 \%)$ studies received a reference standard that either diagnosed or excluded GHD.

\section{Meta-analysis}

Pooled likelihood ratios for test results as well as DORs and $I^{2}$ statistic are reported in Table 2. Figure 2A-D shows summary ROC curves for the tests of interest (restricted to tests that were described in at least three studies).

Pooled sensitivity, specificity, likelihood ratios, and DORs of all studied tests of interest are presented in Table 2. A test with a high likelihood ratio for a positive result indicates that the test is helpful in ruling out disease, while one with a high likelihood ratio for a negative result indicates that the test is helpful in ruling out a disease. A high DOR (above 50) indicates a test that is significantly accurate while correcting for study heterogeneity (8).

\section{Subgroup analysis}

The lack of known pituitary disease was associated with a statistically significant increase in diagnostic accuracy for the serum IGF1 test $(P<0.05)$. All other subgroup analyses explored were not associated with significant test accuracy subgroup interactions $(P>0.05)$. However, the interaction tests are severely underpowered, and therefore, the results may not be reliable (see Supplementary Table 1, see section on supplementary data given at the end of this article).

\section{Discussion}

\section{Summary of findings}

We conducted a systematic review and meta-analysis to evaluate the diagnostic accuracy of tests for GHD. Twenty-three studies provided diagnostic accuracy data; none provided patient outcome data. Studies had fair methodological quality (assessed using the QUADAS checklist), used several reference standards, and included over 1100 patients. Tests involving GH stimulation had good diagnostic accuracy (DOR > 50). Heterogeneity was significant in most analyses. The only significant subgroup interaction was found with relation to serum IGF1 level test and the presence or lack, thereof, of known pituitary disease.

\section{Limitations and strengths}

Inferences presented in this review are limited by the heterogeneity of gold standard definition and cutoffs and in the prevalence of GHD across studies. Imprecision was present in several analyses and lowers the quality of the evidence. This was evident for GHRP6, GHRH, acipimox + GHRH, GHRH + GHRP6, GHRH + GHRP2, hexarelin stimulation, GHRH + clonidine, arginine stimulation, GHRH + pyridostigmine, GHRH + SMS, and glucagon stimulation test that were evaluated in only one or two studies leading to estimates with very wide confidence intervals. Clinicians need to interpret imprecise results with caution and have lower confidence when applying these results at the point of care. Imprecision has likely affected subgroup analyses as well, and a true interaction might have existed but was undetected by the underpowered analyses.

We were unable to evaluate the presence of publication bias because the studies included in each analysis of a diagnostic test were $<20$ and heterogeneity was significant. Under these conditions, all the available methods (funnel plots symmetry, Egger's regression, etc.) are unreliable and function under the wrong assumptions (19).

This review successfully summarizes all available evidence in a systematic (i.e.: protocol-driven) approach leading to reproducible results (20). By restricting our criteria to include studies that had exclusively enrolled patients with a diagnostic uncertainty (21), we have decreased to some extent the overestimation of test accuracy that can otherwise result, namely, in studies that enroll patients who have a pre-established diagnosis of GHD and compare them to healthy adults. 


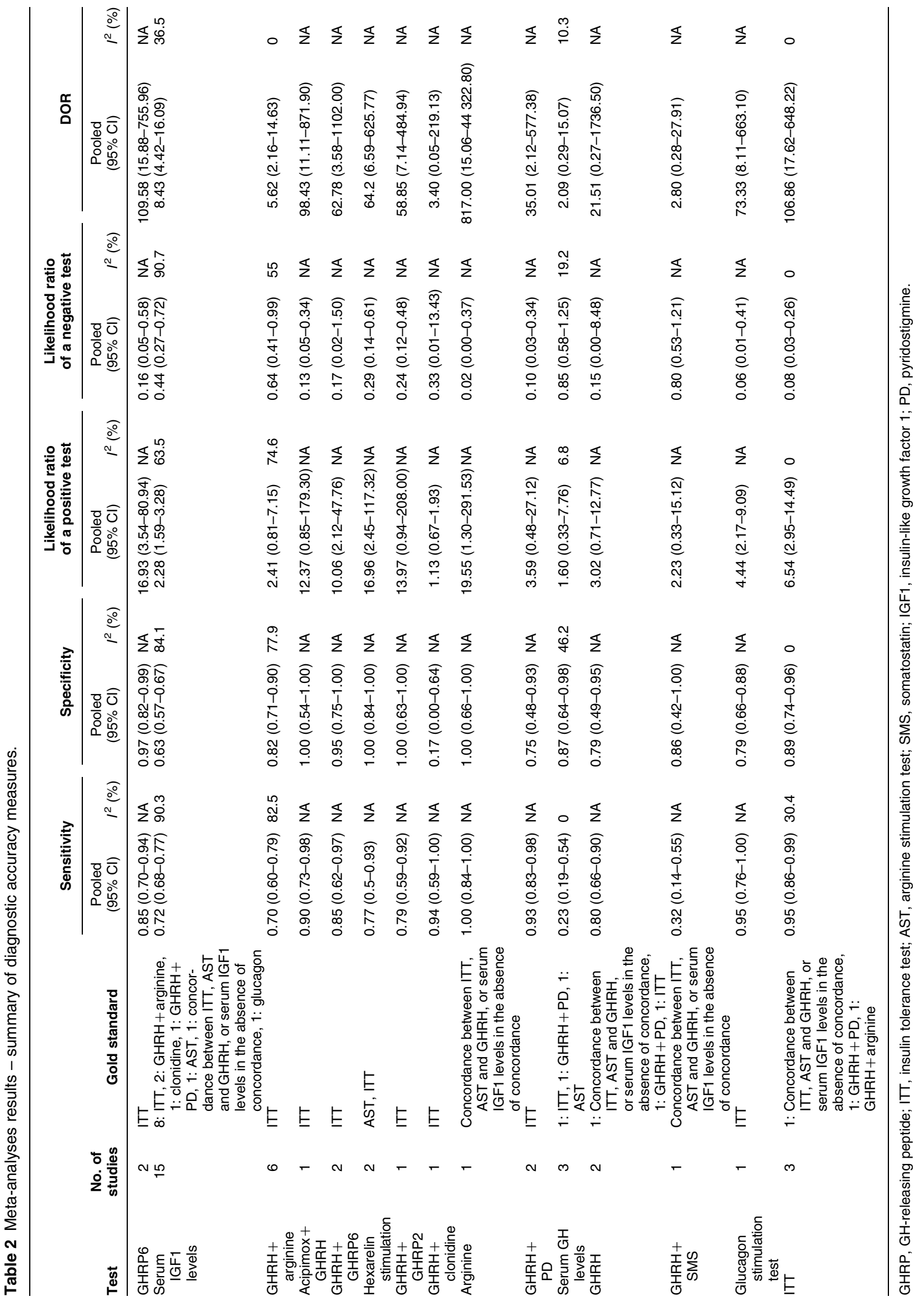



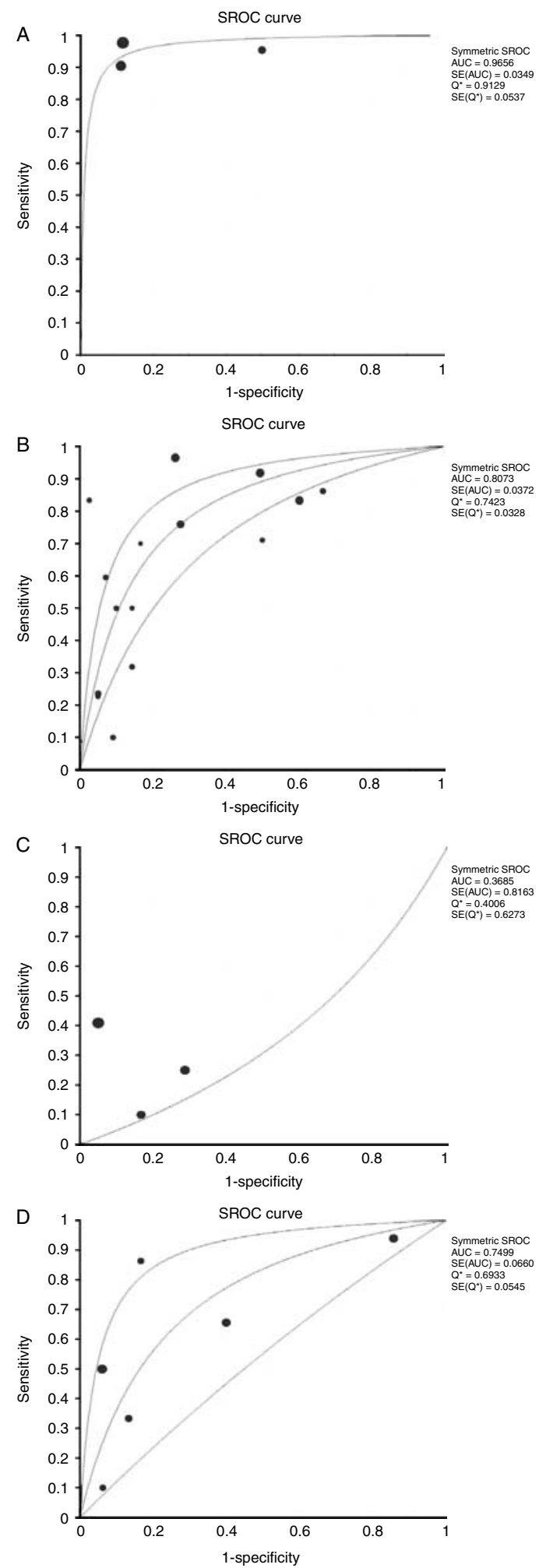

Figure 2 (A) ITT SROC curve. (B) Serum IGF1 SROC curve. (C) GHRH+arginine SROC curve. (D) Serum GH SROC curve.
By using the DOR, we hope to have sufficiently compensated of inconsistencies across included studies, in terms of choice of cutoffs.

\section{Implications for practice and research}

Several clinical practice guidelines on the diagnosis and management of adult GHD recommend the use of provocative tests of GH secretion within an appropriate clinical context and also refer to published diagnostic cutoff criteria $(3,5,22)$. Most of the studies included in this review analyzed the two most commonly recommended tests in these consensus statements, namely the ITT and the GHRH-arginine test, but only the former was reported to have good diagnostic accuracy based on the DOR.

From the clinical practice point of view, it is important to recognize that the diagnostic accuracy of provocative tests of $\mathrm{GH}$ secretion is hampered by a lack of standardization of GH assays (23). Thus, the same patient blood sample sent to different laboratories can yield different $\mathrm{GH}$ concentrations. This discrepancy between $\mathrm{GH}$ assays can be attributed to a number of factors including variable antibody recognition of $\mathrm{GH}$ isoforms, the use of different $\mathrm{GH}$ preparations for calibration, lack of consensus regarding units of measurement for reporting $\mathrm{GH}$, and variability of unit conversion factors (24). It is, therefore, important for clinicians to know which GH analytic method their laboratory uses and whether diagnostic cutoff values for GH provocative tests have been adjusted for that particular assay. Patient characteristics can also influence accuracy of interpretation of GH provocation tests. Obese normal subjects have been shown to exhibit a blunted GH response to provocative stimuli to a degree that sometimes overlaps with the results obtained from severe GH-deficient adults (25). It has, therefore, been suggested that diagnostic cutoff criteria should be adjusted for body mass index to avoid the potential of a false-positive result. Fortunately, IGF1 levels are not low in obese normal patients, and hence, a positive GH stimulation test coupled with a low IGF1 in an obese patient in the appropriate clinical setting is often reassuring to the clinician that the diagnosis of GHD is accurate.

This review's finding of poor diagnostic accuracy of the IGF1 concentration in patients suspected of having GHD is in keeping with reports that IGF1 levels show considerable overlap between normal and GH-deficient adults. Hence, a normal IGF1 level does not rule out GHD. However, the presence of a low IGF1 level in patients with hypopituitarism associated with three or more pituitary hormone deficiencies is considered highly indicative of $\operatorname{GHD}(26,27)$, and clinical guidelines suggest that provocative tests of GH stimulation are optional in such cases. Another confounder when using IGF1 assays is that some reference 
laboratories do not have adequate age-adjusted 95\% confidence intervals.

In this review, many of the analyzed studies used GHRH as part of the stimulus for GH secretion. In practice, clinicians have increasingly adopted the GHRH-arginine test as an alternative to the ITT, which has long been considered the reference standard against which other provocative tests are compared. In addition to its inclusion as a recommended test in clinical consensus guidelines on adult $\operatorname{GHD}(3,5,22)$, the increased popularity of the GHRH-arginine test can likely be attributed to a number of factors including favorable patient tolerability, ease of use, and wider patient applicability compared with the ITT, which is contraindicated in certain clinical situations such as seizure disorders or coronary artery disease. Interestingly, in 2008, the US manufacturer of the recombinant GHRH used in GHD studies made a business decision to indefinitely cease production of GHRH (other forms of GHRH are available outside of the US). The other GH secretagogues used in the studies analyzed by this review are also not available for clinical use in the US. This has now raised the question of which $\mathrm{GH}$ stimulation test should be used in clinical practice when the ITT is contraindicated or cannot be performed due to lack of required resources. Based on the review of available data, Yuen et al. (28) have advocated the glucagon stimulation test as an alternative to the ITT until another recombinant form of GHRH or alternative GH secretagogue becomes available (phase III studies of an oral ghrelin agonist are in process). The American Association of Clinical Endocrinologists has also recommended the glucagon stimulation test in place of the GHRH-AST (22). The advantages of the glucagon test are mainly its wide availability in the United States, the ease with which the $4 \mathrm{~h}$ test can be completed, and its high relative tolerability. We found one recently published study that assessed the diagnostic accuracy of glucagon stimulation test and reported a high sensitivity and specificity and we calculated a DOR of over 70 (29). Two other studies assessed the accuracy of the glucagon stimulation test but had to be excluded from our meta-analysis due to the fact that the studies enrolled patients who had a preestablished diagnosis of $\mathrm{GHD}(30,31)$. The two studies reported sensitivity and specificity ranges of 97-100 and $88-100 \%$ respectively.

\section{Conclusion}

Several GH stimulation tests with fairly good diagnostic accuracy are available for the diagnosis of GHD in adults. The supporting evidence, however, is indirect (as is not directly informative of patient outcomes) and at high risk of bias.

\section{Supplementary data}

This is linked to the online version of the paper at http://dx.doi.org/10. 1530/EJE-11-0476.

\section{Declaration of interest}

The authors declare that there is no conflict of interest that could be perceived as prejudicing the impartiality of the research reported.

\section{Funding}

This review was commissioned and funded by a contract for the Endocrine Society (Grant no.: not applicable).

\section{References}

1 Aimaretti G, Corneli G, Razzore P, Bellone S, Baffoni C, Arvat E, Camanni $\mathrm{F} \&$ Ghigo E. Comparison between insulin-induced hypoglycemia and growth hormone (GH)-releasing hormone+ arginine as provocative tests for the diagnosis of GH deficiency in adults. Journal of Clinical Endocrinology and Metabolism $1998 \mathbf{8 3}$ 1615-1618. (doi:10.1210/jc.83.5.1615)

2 Colao A, Vitale G, Pivonello R, Ciccarelli A, Di Somma C \& Lombardi G. The heart: an end-organ of GH action. European Journal of Endocrinology 2004151 (Suppl 1) S93-S101. (doi:10. 1530/eje.0.151S093)

3 Molitch ME, Clemmons DR, Malozowski S, Merriam GR, Shalet SM, Vance ML \& Stephens PA. Evaluation and treatment of adult growth hormone deficiency: an Endocrine Society Clinical Practice Guideline. Journal of Clinical Endocrinology and Metabolism 200691 1621-1634. (doi:10.1210/jc.2005-2227)

4 Liu H, Bravata DM, Olkin I, Nayak S, Roberts B, Garber AM \& Hoffman AR. Systematic review: the safety and efficacy of growth hormone in the healthy elderly. Annals of Internal Medicine 2007 $146104-115$.

5 Ho KK. Consensus guidelines for the diagnosis and treatment of adults with GH deficiency II: a statement of the GH Research Society in association with the European Society for Pediatric Endocrinology, Lawson Wilkins Society, European Society of Endocrinology, Japan Endocrine Society, and Endocrine Society of Australia. European Journal of Endocrinology 2007157 695-700. (doi:10.1530/EJE-07-0631)

6 Deville WL, Buntinx F, Bouter LM, Montori VM, de Vet HC, van der Windt DA \& Bezemer PD. Conducting systematic reviews of diagnostic studies: didactic guidelines. BMC Medical Research Methodology 20022 9. (doi:10.1186/1471-2288-2-9)

7 Lijmer JG, Mol BW, Heisterkamp S, Bonsel GJ, Prins MH, van der Meulen JH \& Bossuyt PM. Empirical evidence of design-related bias in studies of diagnostic tests. Journal of the American Medical Association 1999282 1061-1066. (doi:10.1001/jama.282.11. 1061)

8 Glas AS, Lijmer JG, Prins MH, Bonsel GJ \& Bossuyt PM. The diagnostic odds ratio: a single indicator of test performance. Journal of Clinical Epidemiology 200356 1129-1135. (doi:10. 1016/S0895-4356(03)00177-X)

9 Darzy KH, Aimaretti G, Wieringa G, Gattamaneni HR, Ghigo E \& Shalet SM. The usefulness of the combined growth hormone (GH)releasing hormone and arginine stimulation test in the diagnosis of radiation-induced GH deficiency is dependent on the postirradiation time interval. Journal of Clinical Endocrinology and Metabolism 200388 95-102. (doi:10.1210/jc.2002-021094)

10 Altman DG \& Bland JM. Interaction revisited: the difference between two estimates. BMJ $2003 \mathbf{3 2 6}$ 219. (doi:10.1136/bmj. 326.7382.219)

11 Aimaretti G, Baffoni C, Bellone S, Di Vito L, Corneli G, Arvat E, Benso L, Camanni F \& Ghigo E. Retesting young adults with 
childhood-onset growth hormone (GH) deficiency with GH-releasing-hormone-plus-arginine test. Journal of Clinical Endocrinology and Metabolism 200085 3693-3699. (doi:10.1210/jc.85.10. 3693)

12 Biller BM, Samuels MH, Zagar A, Cook DM, Arafah BM, Bonert V, Stavrou S, Kleinberg DL, Chipman JJ \& Hartman ML. Sensitivity and specificity of six tests for the diagnosis of adult GH deficiency. Journal of Clinical Endocrinology and Metabolism $2002 \mathbf{8 7}$ 2067-2079. (doi:10.1210/jc.87.5.2067)

13 Brennan BM, Rahim A, Mackie EM, Eden OB \& Shalet SM. Growth hormone status in adults treated for acute lymphoblastic leukaemia in childhood. Clinical Endocrinology $1998 \mathbf{4 8}$ 777-783. (doi:10.1046/j.1365-2265.1998.00438.x)

14 Fisker S, Jorgensen JO, Orskov H \& Christiansen JS. L-arginine and insulin-tolerance tests in the diagnosis of adult growth hormone deficiency: influence of confounding factors. Clinical Endocrinology 199848 109-115. (doi:10.1046/j.1365-2265.1998.00362.x)

15 Korbonits M, Kaltsas G, Perry LA, Grossman AB, Monson JP, Besser GM \& Trainer PJ. Hexarelin as a test of pituitary reserve in patients with pituitary disease. Clinical Endocrinology 199951 369-375. (doi:10.1046/j.1365-2265.1999.00828.x)

16 Lissett CA, Thompson EG, Rahim A, Brennan BM \& Shalet SM. How many tests are required to diagnose growth hormone (GH) deficiency in adults? Clinical Endocrinology 199951 551-557. (doi:10.1046/j.1365-2265.1999.00836.x)

17 Lissett CA. Unusual aspects of GH re-testing. International Journal of Clinical Practice 2002126 14-17.

18 Lissett CA, Saleem S, Rahim A, Brennan BM \& Shalet SM. The impact of irradiation on growth hormone responsiveness to provocative agents is stimulus dependent: results in 161 individuals with radiation damage to the somatotropic axis. Journal of Clinical Endocrinology and Metabolism 200186 663-668. (doi:10.1210/jc.86.2.663)

19 Deeks JJ, Macaskill P \& Irwig L. The performance of tests of publication bias and other sample size effects in systematic reviews of diagnostic test accuracy was assessed. Journal of Clinical Epidemiology 200558 882-893. (doi:10.1016/j.jclinepi.2005. 01.016)

20 Montori VM \& Guyatt GH. Summarizing studies of diagnostic test performance. Clinical Chemistry 200349 1783-1784. (doi:10. 1373/clinchem.2003.024935)

21 Sackett DL \& Haynes RB. The architecture of diagnostic research. BMJ 2002324 539-541. (doi:10.1136/bmj.324.7336.539)

22 Cook DM, Yuen KC, Biller BM, Kemp SF \& Vance ML. American Association of Clinical Endocrinologists medical guidelines for clinical practice for growth hormone use in growth hormonedeficient adults and transition patients - 2009 update. Endocrine Practice 200915 (Suppl 2) 1-29.

23 Bidlingmaier M. Problems with GH assays and strategies toward standardization. European Journal of Endocrinology 2008159 (Suppl 1) S41-S44. (doi:10.1530/EJE-08-0284)

24 Sheppard MC. Growth hormone assay standardization: an important clinical advance. Clinical Endocrinology 200766 157-161. (doi:10.1111/j.1365-2265.2007.02703.x)

25 Corneli G, Gasco V, Prodam F, Grottoli S, Aimaretti G \& Ghigo E. Growth hormone levels in the diagnosis of growth hormone deficiency in adulthood. Pituitary 200710 141-149. (doi:10. 1007/s11102-007-0031-0)

26 Toogood AA, Beardwell CG \& Shalet SM. The severity of growth hormone deficiency in adults with pituitary disease is related to the degree of hypopituitarism. Clinical Endocrinology $1994 \mathbf{4 1}$ 511-516. (doi:10.1111/j.1365-2265.1994.tb02583.x)

27 Hartman ML, Crowe BJ, Biller BM, Ho KK, Clemmons DR \& Chipman JJ. Which patients do not require a GH stimulation test for the diagnosis of adult GH deficiency? Journal of Clinical Endocrinology and Metabolism 200287 477-485. (doi:10.1210/ jc.87.2.477)

28 Yuen KC, Biller BM, Molitch ME \& Cook DM. Clinical review: is lack of recombinant growth hormone (GH)-releasing hormone in the
United States a setback or time to consider glucagon testing for adult GH deficiency? Journal of Clinical Endocrinology and Metabolism 200994 2702-2707. (doi:10.1210/jc.2009-0299)

29 Berg C, Meinel T, Lahner H, Yuece A, Mann K \& Petersenn S. Diagnostic utility of the glucagon stimulation test in comparison to the insulin tolerance test in patients following pituitary surgery. European Journal of Endocrinology 2010162 477-482. (doi:10. 1530/EJE-09-0824)

30 Conceicao FL, da Costa e Silva A, Leal Costa AJ \& Vaisman M. Glucagon stimulation test for the diagnosis of GH deficiency in adults. Journal of Endocrinological Investigation $2003 \mathbf{2 6}$ 1065-1070.

31 Gomez JM, Espadero RM, Escobar-Jimenez F, Hawkins F, Pico A, Herrera-Pombo JL, Vilardell E, Duran A, Mesa J, Faure E \& Sanmarti A. Growth hormone release after glucagon as a reliable test of growth hormone assessment in adults. Clinical Endocrinology 200256 329-334. (doi:10.1046/j.1365-2265.2002. 01472.x)

32 Alaioubi B, Mann K \& Petersenn S. Diagnosis of growth hormone deficiency in adults: provocative testing with GHRP6 in comparison to the insulin tolerance test. Hormone and Metabolic Research 200941 238-243. (doi:10.1055/s-0028-1093350)

33 Andersen M, Hansen TB, Stoving RK, Bertelsen J, Hangaard J, Hyltoft Petersen P \& Hagen C. The pyridostigmine-growthhormone-releasing-hormone test in adults. The reference interval and a comparison with the insulin tolerance test. Endocrinology and Metabolism 19963 197-206.

34 Beentjes JAM, Tjeerdsma G, Sluiter WJ \& Dullaart RPF. Divergence between growth hormone responses to insulin-induced hypoglycaemia and growth hormone-releasing hormone in patients with non-functioning pituitary macroadenomas and hyperprolactinaemia. Clinical Endocrinology 199645 391-398. (doi:10.1046/j. 1365-2265.1996.8210831.x)

35 Bjork J, Link K \& Erfurth EM. The utility of the growth hormone (GH) releasing hormone-arginine test for diagnosing $\mathrm{GH}$ deficiency in adults with childhood acute lymphoblastic leukemia treated with cranial irradiation. Journal of Clinical Endocrinology and Metabolism 200590 6048-6054. (doi:10.1210/jc.20050304)

36 Colao A, Cerbone G, Pivonello R, Klain M, Aimaretti G, Faggiano A, Di Somma C, Salvatore M \& Lombardi G. Growth hormone deficiency in elderly patients with hypothalamopituitary tumors. Pituitary 1998 1 59-67. (doi:10.1023/ A:1009923025853)

37 Corneli G, Di Somma C, Prodam F, Bellone J, Bellone S, Gasco V, Baldelli R, Rovere S, Schneider HJ, Gargantini L, Gastaldi R, Ghizzoni L, Valle D, Salerno M, Colao A, Bona G, Ghigo E, Maghnie M \& Aimaretti G. Cut-off limits of the GH response to GHRH plus arginine test and IGF-I levels for the diagnosis of GH deficiency in late adolescents and young adults. European Journal of Endocrinology 2007157 701-708. (doi:10.1530/EJE-07-0384)

38 Darzy KH, Thorner MO \& Shalet SM. Cranially irradiated adult cancer survivors may have normal spontaneous GH secretion in the presence of discordant peak $\mathrm{GH}$ responses to stimulation tests (compensated GH deficiency). Clinical Endocrinology 200970 287-293. (doi:10.1111/j.1365-2265.2008.03359.x)

39 Hadjadj S, Faure-Gerard C, Ragot S, Millet C, Duengler F, Torremocha F, Chatellier G, Bataille B \& Marechaud R. Diagnostic strategy for growth hormone deficiency: relevance of IGF-1 determination as a screening test. Annales d'Endocrinologie 2007 68 449-455. (doi:10.1016/j.ando.2007.08.004)

40 Hoeck HC, Vestergaard P, Jakobsen PE, Falhof J \& Laurberg P. Diagnosis of growth hormone $(\mathrm{GH})$ deficiency in adults with hypothalamic-pituitary disorders: comparison of test results using pyridostigmine plus GH-releasing hormone (GHRH), clonidine plus GHRH, and insulin-induced hypoglycemia as GH secretagogues. Journal of Clinical Endocrinology and Metabolism $2000 \mathbf{8 5}$ 1467-1472. (doi:10.1210/jc.85.4.1467)

41 Juul A, Kastrup KW, Pedersen SA \& Skakkebaek NE. Growth hormone $(\mathrm{GH})$ provocative retesting of 108 young adults with childhood-onset GH deficiency and the diagnostic value of insulin-like 
growth factor I (IGF-I) and IGF-binding protein-3. Journal of Clinical Endocrinology and Metabolism 199782 1195-1201. (doi:10.1210/jc.82.4.1195)

42 Longobardi S, Merola B, Pivonello R, DiRella F, DiSomma C, Colao A, Ghigo E, Camanni F \& Lombardi G. Reevaluation of growth hormone $(\mathrm{GH})$ secretion in 69 adults diagnosed as GH-deficient patients during childhood. Journal of Clinical Endocrinology and Metabolism 199681 1244-1247. (doi:10. $1210 /$ jc. 81.3 .1244$)$

43 Mahajan T \& Lightman SL. A simple test for growth hormone deficiency in adults. Journal of Clinical Endocrinology and Metabolism 200085 1473-1476. (doi:10.1210/jc.85.4.1473)

44 Murray RD, Peacey SR, Rahim A, Toogood AA, Thorner MO \& Shalet SM. The diagnosis of growth hormone deficiency (GHD) in successfully treated acromegalic patients. Clinical Endocrinology 200154 37-44. (doi:10.1046/j.1365-2265.2001.01189.x)

45 Petersenn S, Jung R \& Beil FU. Diagnosis of growth hormone deficiency in adults by testing with GHRP-6 alone or in combination with GHRH: comparison with the insulin tolerance test. European Journal of Endocrinology 2002146 667-672. (doi:10.1530/eje.0.1460667)

46 Popovic V, Pekic S, Golubicic I, Doknic M, Dieguez C \& Casanueva FF. The impact of cranial irradiation on $\mathrm{GH}$ responsiveness to GHRH plus GH-releasing peptide-6. Journal of Clinical Endocrinology and Metabolism 200287 2095-2099. (doi:10.1210/jc.87.5.2095)

47 Schneider HJ, Herrmann BL, Schneider M, Sievers C, Schaaf L \& Stalla GK. Discrepant results in the diagnosis of GH deficiency with the insulin-tolerance test and the GHRH plus arginine test in patients with traumatic brain injury. European Journal of Endocrinology 2006155 553-557. (doi:10.1530/eje.1.02258)

48 Schutz F, Wuster C, Heilmann P, Ziegler R \& Hadji P. No advantage of the new combined octreotide-GHRH test over established GH-stimulation tests in the diagnosis of growth hormone deficiency (GHD) in adults. Clinical Endocrinology 200053 667-674. (doi:10.1046/j.1365-2265.2000.01113.x)

49 van Dam PS, Dieguez C, Cordido F, de Vries WR, Veldhuyzen BF, van Thiel E, Casanueva FF \& Koppeschaar HP. Diagnosis of growth hormone deficiency after pituitary surgery: the combined acipimox/GH-releasing hormone test. Clinical Endocrinology 200358 156-162. (doi:10.1046/j.1365-2265.2003.01684.x)

50 Vannelli S, Stasiowska B, Bellone J, Aimaretti G, Bellone S, Avataneo T, Cirillo S \& Benso L. Is the persistence of isolated GH deficiency in adulthood predicted by anatomical hypothalamic-pituitary alterations? Journal of Endocrinological Investigation 199720 312-318.

51 Zgaljardic DJ, Guttikonda S, Grady JJ, Gilkison CR, Mossberg KA, High WM Jr, Masel BE \& Urban RJ. Serum IGF-1 concentrations in a sample of patients with traumatic brain injury as a diagnostic marker of growth hormone secretory response to glucagon stimulation testing. Clinical Endocrinology 201174 365-369. (doi:10.1111/j.1365-2265.2010.03935.x)

Received 29 May 2011

Revised version received 18 August 2011

Accepted 19 August 2011 